\title{
Vardenafil demonstrates first-dose success and reliability of penetration and maintenance of erection in men with erectile dysfunction - RELY-II
}

\author{
Luc Valiquette, MD; ${ }^{*}$ Francesco Montorsi, MD; ${ }^{\dagger}$ Stephen Auerbach, MD; ${ }^{;}$for the Vardenafil Study Group
}

See related article on page 196

\section{Abstract}

Objective: Vardenafil has been shown to be efficacious in patients with erectile dysfunction (ED). We evaluated first-dose and repeat-dose response to vardenafil $20 \mathrm{mg}$.

Methods: This randomized, placebo-controlled study consisted of a 4-week, treatment-free run-in phase; a 1-week, open-label challenge phase; and a 12-week, double-blind treatment phase. Primary efficacy was assessed in terms of reliability of insertion based on dose as measured by the Sexual Encounter Profile question 2 (SEP2). We assessed safety by evaluating adverse events (AEs).

Results: Baseline patient characteristics in the 2 treatment groups were similar. The most common comorbidities were hypertension $(41 \%)$, dyslipidemia $(28 \%)$ and diabetes mellitus (24\%). Of the 573 patients receiving the 20-mg vardenafil challenge dose, $464(81 \%)$ achieved first-time successful penetration (SEP2), and 401 (70\%) reported successful erection maintenance (SEP3). Patients receiving vardenafil $20 \mathrm{mg}$ had statistically $(p<0.001)$ and clinically superior SEP2 rates (85\%) through weeks 0-12, compared with patients receiving placebo $(45 \%)$. The increase in reliability of insertion was seen within the first 4 weeks of treatment. Vardenafil therapy was statistically $(p<0.001)$ and clinically superior to placebo for all secondary efficacy end points as well. Most AEs associated with vardenafil were mild to moderate, with headache, flushing and nasal congestion most frequently reported.

Conclusion: Vardenafil $20 \mathrm{mg}$ had a high first-dose success rate for both SEP2 (81\%) and SEP3 (70\%); this was maintained through to the study end point $(85 \%$ for SEP2 and 78\% for SEP3). These findings were achieved in men with frequently associated comorbidities including hypertension, dyslipidemia and diabetes.

CUAJ 2008;2(3):187-95

\section{Introduction}

Erectile dysfunction (ED) is a highly prevalent condition that has a major impact on the lives of millions of men and their partners, affecting sexual and psychological health and quality of life (QOL). ${ }^{1-3}$ Depending on the etiology, ED may indicate underlying systemic vascular or neurogenic disease that is often associated with the impairment of neurogenic and/or endothelium-dependent vasodilatory mechanisms, which in turn contribute to circulatory and structural changes in penile tissues. ${ }^{4-8}$ The resulting arterial insufficiency and defective smooth muscle relaxation in men with vascular comorbidities lead to an increased prevalence of ED in this patient population, which complicates disease management. ${ }^{4-6}$

Most men with ED have concomitant comorbidities, and the etiology of disease in men with ED and comorbidities is more severe than in men who have ED alone. .-6,9-12 $^{-12}$ One particular study reported that up to $70 \%$ of men with ED also had one or more of the following comorbidities: hypertension, diabetes, dyslipidemia or depression. ${ }^{9}$ Data from a study by Greenstein and colleagues ${ }^{13}$ demonstrated a correlation between the severity of ED (assessed with a questionnaire introduced by $\mathrm{O}^{\prime}$ Leary and colleagues ${ }^{14}$ ) and the severity of coronary artery disease (CAD; classified according to the New York Heart Association functional classification). ${ }^{15}$ After a 30-day period during which patients were expected to maintain a normal pattern of sexual activity with their spouse or partner, the results showed that patients with CAD affecting only 1 coronary vessel had a significantly increased number of erections $(p<0.04)$, along with firmer erections $(p<0.001)$ and fewer difficulties in achieving an erection $(p<$ $0.007)$, compared with men who had 2 or 3 coronary vessels involved. ${ }^{13}$

First-time or rapid onset and continued success or reliability (the ability of a patient with ED to respond to subsequent therapy after an initial positive treatment response) are important criteria for selecting and 
continuing treatment in ED patients with comorbidities. ${ }^{16}$ Optimal ED therapy with a phosphodiesterase type 5 (PDE5) inhibitor would result in substantial initial response to therapy and provide consistent long-term reliability and improvement in overall QOL. ${ }^{17}$ The reliability of ED therapy therefore improves patients' confidence in and compliance with it and may reduce the incidence of treatment discontinuation owing to lack of effect. ${ }^{18}$ In the Men's Attitudes to Life Events and Sexuality (MALES) study, 47\% of 3291 men with ED indicated that therapy reliability after initial response was among the most important characteristics of therapy, and 255 (22\%) stated that they discontinued treatment because their medication only worked occasionally. ${ }^{19-21}$

Demonstrating first-time dose success and reliability in ED populations is often challenging because of the complicating pathophysiology of the disease, which may be even more challenging to treat in men with comorbid conditions. The Reliability-Vardenafil for Erectile Dysfunction I (RELY-I) study showed that vardenafil $10 \mathrm{mg}$ was highly successful as a first-dose therapy in terms of key erection function parameters and that it provided reliability for ED patients both with and without comorbid conditions. ${ }^{21,22}$ Similar in design to RELY-I and conducted simultaneously, RELY-II was a prospective, placebo-controlled, clinical trial designed to assess the first-time dose response and overall reliability of vardenafil $20 \mathrm{mg}$ in men with ED and specific comorbidities that included hypertension, dyslipidemia and diabetes mellitus. In contrast to the men randomized in the RELY-I study, the patient population in the RELY-II study had a higher percentage of men with severe ED, including those with comorbidities.

\section{Methods}

This study was conducted in compliance with the human experimentation guidelines of the US Department of Health and Human Services and the Helsinki Declaration 1975, last amended in 2000 in Edinburgh, Scotland.

\section{Study objectives}

The primary objective of this study was to assess first-dose success and reliability of vardenafil $20 \mathrm{mg}$ in men with ED through 12 weeks of treatment in a placebo-controlled clinical trial. The secondary objective was to evaluate the safety and tolerability of vardenafil $20 \mathrm{mg}$ compared with placebo.

\section{Study design}

RELY-II was a 12-week, multicentre, randomized, double-blind, parallel-group, placebo-controlled trial in vardenafil-naive patients. At screening, patients were entered into a 4-week, treatmentfree, run-in phase and instructed to make at least 4 attempts at sexual intercourse on 4 separate days. A diary was provided for patients to record all attempts made at sexual intercourse. The patients who failed at $50 \%$ or more of their attempts at intercourse were entered into a 1-week challenge phase. Patients were then instructed to make at least 1 attempt at sexual intercourse 1 hour after administration of a single 20-mg dose of vardenafil. Medication was to be taken without regard to meals. Patients with a positive response to question 2 of the Sexual Encounter Profile (SEP2) ("Were you able to insert your penis into your partner's vagina?") in regard to attempts made 0.5 to 6 hours after ingestion of the study medication were randomized to receive either vardenafil $20 \mathrm{mg}$ or placebo for 12 weeks. Patients were instructed to take each dose of medication without regard to meals, on an as-needed basis 1 hour before attempting sexual intercourse, with only 1 dose permitted per day. Patients recorded the date and time at which they took the study medication, the time at which they attempted sexual intercourse and their responses to questions regarding success at penetration (SEP2) and maintenance of erection sufficient enough for completion of intercourse (SEP3: "Did your erection last long enough for you to have successful intercourse?"). During the 12-week treatment period, patients were scheduled for study visits at weeks 4,8 and 12 for assessment of efficacy, safety, tolerability and compliance.

\section{Patient population and demographics}

This study included male patients with a diagnosis of ED lasting more than 6 months, defined according to the National Institutes of Health Consensus Statement (the inability to attain or maintain penile erection sufficient for satisfactory sexual performance). ${ }^{2}$ Patients had to be aged 18 years or older and in a heterosexual relationship 
and to have completed written informed consent before study entry. For randomization into the treatment phase of the trial, patients had to have been unsuccessful in at least 2 of the 4 attempts at intercourse during the 4-week treatment-free period. They also had to be successful during the challenge phase assessed by the SEP2 question and to have an International Index of Erectile Function-Erectile Function (IIEF-EF) domain score of 5 or more and less than 26 at the start of the challenge phase.

\section{Efficacy assessment}

During the challenge phase, SEP2 and SEP3 firstdose success rates were stratified according to comorbidities, and in the treatment phase, patients were assessed on SEP2 and SEP3 success rates. The primary efficacy end point was reliability of insertion as assessed by a positive SEP2 response after each dose of study medication. Secondary efficacy end points included reliability of maintained erection up to completion of intercourse (assessed by SEP3) and IIEF-EF domain score.

\section{Safety assessment}

The safety population included all patients who were administered 1 or more dose(s) of vardenafil therapy or placebo and who had any treatmentperiod data collected. Safety and tolerability were evaluated throughout the study by assessing adverse events (AEs) from the start of the challenge phase to the end of week 12. Clinical chemistry, hematology, urinalysis, complete physical examination, 12-lead electrocardiogram and vital signs were also used as part of the safety assessments.

\section{Statistical methods}

The primary population for the efficacy analysis was the intent-to-treat (ITT) population, which consisted of randomized patients who took at least 1 dose of either vardenafil or placebo and had postrandomization efficacy data collected. Similarly, the primary population for the safety assessment included all randomized patients who took at least 1 dose of study medication and had any safety data collected during the treatment period. The study was designed to detect a clinically meaningful treatment difference in SEP2 reliability of 15.0 (standard deviation 35.0 ) in the mean proportion of successes at 12 weeks, with $96 \%$ power and an $\alpha$ level of 0.05 . We used analysis of covariance (ANCOVA) with adjusting for baseline values to compare the mean proportions of success for each treatment group. Secondary efficacy variables were analyzed with ANCOVA or logistic regression.

\section{Results}

\section{Patient demographics}

The study enrolled a relatively higher percentage of patients having comorbidities associated with endothelial dysfunction than the RELY-I study that had a similar design. ${ }^{21,22}$ Of the 573 men who received a single 20-mg dose of vardenafil in the challenge phase, $41 \%$ had hypertension, $28 \%$ had dyslipidemia, and $24 \%$ had diabetes mellitus. Of these patients, 230 were randomized to receive vardenafil $20 \mathrm{mg}$, and 233 were randomized to placebo. The ITT population consisted of 223 patients randomized to vardenafil $20 \mathrm{mg}$ and 226 to placebo. The baseline demographic characteristics were similar between the treatment groups. Overall, patients had a mean age of 56 years, mean weight of $85 \mathrm{~kg}$ and mean body mass index of 28 . Most patients were of European (63\%) or Asian $(23 \%)$ ethnicity. Of all patients enrolled in the study, 83\% either abstained or had light alcohol use; there were slightly more smokers or former smokers (56\%) than nonsmokers (44\%). The baseline disease characteristics were similar between the treatment groups. The mean baseline IIEF-EF domain score was similar between the placebo (12.9) and vardenafil (13.1) groups, indicative of moderately severe ED. Most patients had a baseline ED severity category of moderate (placebo group, 32\%; vardenafil group, 39\%) or severe (placebo group, 37\%; vardenafil group, 31\%). A majority of patients in both treatment groups had ED of either organic (placebo group, 57\%; vardenafil group, 53\%) or mixed (placebo group, $36 \%$; vardenafil group, $41 \%$ ) causes. Overall, the mean duration of ED was 5.9 years. Of the patients, $90 \%$ on placebo and $89 \%$ on vardenafil had at least a single comorbidity at baseline. Specific comorbidity histories were similar between the treatment groups for all conditions except that back 
pain, headache and dyspepsia were common in the vardenafil group, whereas benign prostatic hyperplasia (BPH), dyslipidemia, hypermetropia and drug hypersensitivity were common in the placebo group. Table 1 shows baseline demographic and disease characteristics.

The incidence of prior sildenafil and tadalafil use was similar between the treatment groups. In both treatment groups, $78 \%$ had used sildenafil previously, while $93 \%$ in the placebo group and $90 \%$ in the vardenafil group had not used tadalafil. Generally, insufficient effect was the most common reason patients reported for stopping either sildenafil or tadalafil therapy before enrolment.

A total of 196 patients randomized to vardenafil and 188 randomized to placebo completed the study. More patients in the placebo group $(19 \%)$ than in the vardenafil group $(15 \%)$ prematurely discontinued the study. This difference between the treatment groups was mainly due to patients withdrawing because of insufficient therapeutic effect (placebo group, 8\%; vardenafil group, $2 \%$ ). More patients in the vardenafil group $(4 \%)$ than in the placebo group $(1 \%)$ were withdrawn because of a protocol violation. In addition, 10 patients discontinued during the vardenafil challenge period: 5 withdrew their consent, 2 withdrew as a result of AEs, 2 withdrew because of the amended safety criteria, and 1 withdrew because of insufficient therapeutic effect (Fig. 1).

\section{Efficacy}

Of the 573 patients who received the 20-mg challenge of vardenafil, 464 (81\%) achieved first-time success for penetration (SEP2) and 401 (70\%) reported successful erection maintenance (SEP3). We stratified first-dose success data for vardenafil $20 \mathrm{mg}$ according to specific comorbidities. For patients with comorbidities, respective first-dose

Table 1. Baseline demographics and disease characteristics

\begin{tabular}{|c|c|c|c|}
\hline \multirow[b]{2}{*}{ Variable } & \multicolumn{3}{|c|}{ Group; no. (and \%)* } \\
\hline & Placebo; $n=226$ & Vardenafil; $n=223$ & Total; $n=449$ \\
\hline \multicolumn{4}{|l|}{ Age, yr } \\
\hline Mean (SD) & $55.9(11.8)$ & $55.2(11.2)$ & $55.6(11.5)$ \\
\hline Range & 22-81 & 23-86 & 22-86 \\
\hline \multicolumn{4}{|l|}{ Ethnicity } \\
\hline European & $144(64)$ & $138(62)$ & $282(63)$ \\
\hline Asian & $53(23)$ & $49(22)$ & $102(23)$ \\
\hline Black & $12(5)$ & $22(10)$ & $34(8)$ \\
\hline Hispanic & $15(7)$ & $12(5)$ & $27(6)$ \\
\hline Other & $2(<1)$ & $2(<1)$ & $4(<1)$ \\
\hline \multicolumn{4}{|l|}{ Weight, kg } \\
\hline Mean (SD) & $83.7(17.4)$ & $85.6(16.9)$ & $84.6(17.1)$ \\
\hline Range & 50-160 & 50-132 & 50-160 \\
\hline \multicolumn{4}{|l|}{ Height, cm } \\
\hline Mean (SD) & $174.3(7.9)$ & $174.8(7.7)$ & $174.6(7.8)$ \\
\hline Range & 152-197 & 155-196 & 152-197 \\
\hline \multicolumn{4}{|l|}{ Body mass index, $\mathrm{kg} / \mathrm{m}^{2}$} \\
\hline Mean (SD) & $24.7(4.5)$ & $27.9(4.8)$ & $27.7(4.7)$ \\
\hline Range & 19-48 & $18-46$ & 18-48 \\
\hline \multicolumn{4}{|l|}{ Alcohol use } \\
\hline Abstinent & $74(33)$ & 76 (34) & $150(33)$ \\
\hline Light & $116(51)$ & $108(48)$ & $224(50)$ \\
\hline Moderate & $34(15)$ & $35(16)$ & $69(15)$ \\
\hline Heavy & $2(<1)$ & $4(2)$ & $6(1)$ \\
\hline \multicolumn{4}{|l|}{ Smoking status } \\
\hline \multirow[t]{2}{*}{ Past or present smoker } & $125(55)$ & $125(56)$ & $250(56)$ \\
\hline & & & Continued on next page \\
\hline
\end{tabular}


SEP2 and SEP3 success rates were as follows: $76 \%$ and $64 \%$ with hypertension $(n=255), 75 \%$ and $63 \%$ with dyslipidemia $(n=177), 76 \%$ and $66 \%$ with $\mathrm{BPH}(n=109)$, and $72 \%$ and $60 \%$ with diabetes mellitus $(n=149)$. For patients without comorbidities, respective first-dose SEP2 and SEP3 success rates were as follows: $85 \%$ and $75 \%$ for patients without hypertension $(n=318), 84 \%$ and $73 \%$ for patients without dyslipidemia $(n=396)$, $82 \%$ and $71 \%$ for patients without BPH $(n=463)$, and $84 \%$ and $74 \%$ for patients without diabetes mellitus ( $n=424)$ (Fig. 2). Therefore, vardenafil $20 \mathrm{mg}$ was effective in treating ED in patients with and without the aforementioned comorbidities.

Over the 12 weeks of treatment, patients receiving vardenafil had statistically and clinically superior reliability of insertion (85\%), compared with patients receiving placebo $(45 \% ; p<0.001)$. An increase in reliability was seen within the first 4 weeks of treatment. Subsequent SEP3 reliability

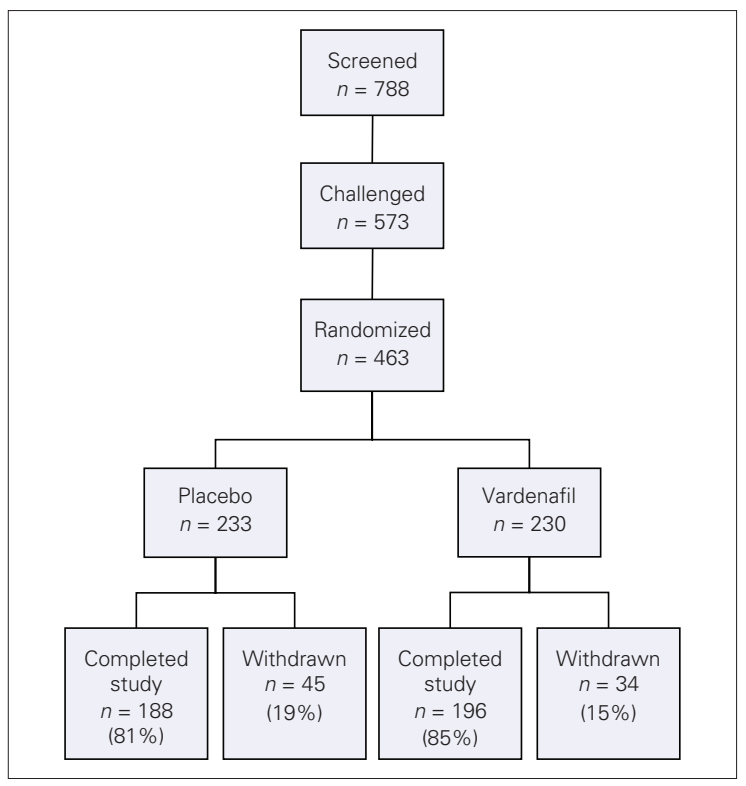

Fig. 1. Disposition of patients from study enrolment through endpoint.

Table 1. continued

\begin{tabular}{|c|c|c|c|}
\hline \multirow[b]{2}{*}{ Variable } & \multicolumn{3}{|c|}{ Group; no. (and \%)* } \\
\hline & Placebo; $n=226$ & Vardenafil; $n=223$ & Total; $n=449$ \\
\hline \multicolumn{4}{|l|}{ Smoking status } \\
\hline Nonsmoker & $100(44)$ & $98(44)$ & $198(44)$ \\
\hline Passive smoker & $1(<1)$ & 0 & $1(<1)$ \\
\hline \multicolumn{4}{|l|}{ ED severity } \\
\hline No attempts $(\leq 5)$ & $3(1)$ & $6(3)$ & $9(2)$ \\
\hline Severe $(6-10)$ & $84(37)$ & $70(31)$ & $154(34)$ \\
\hline Moderate (11-16) & $72(32)$ & 87 (39) & $159(35)$ \\
\hline Mild-moderate (17-21) & $57(25)$ & $44(20)$ & $101(22)$ \\
\hline Mild (22-25) & $10(4)$ & $15(7)$ & $25(6)$ \\
\hline No ED/normal (> 25) & 0 & $1(<1)$ & $1(<1)$ \\
\hline \multicolumn{4}{|l|}{ Etiology } \\
\hline Organic & $129(57)$ & $118(53)$ & $247(55)$ \\
\hline Psychogenic & $16(7)$ & $14(6)$ & $30(7)$ \\
\hline Mixed & $81(36)$ & $91(41)$ & $172(38)$ \\
\hline \multicolumn{4}{|l|}{ Time since ED diagnosis, yr } \\
\hline No. & 226 & 222 & 448 \\
\hline Mean (SD) & $3.6(3.6)$ & $3.8(3.3)$ & $3.7(3.5)$ \\
\hline Range & 0-31 & 0-21 & 0-31 \\
\hline \multicolumn{4}{|c|}{ Time since ED first noticed, yr } \\
\hline Mean (SD) & $5.6(4.4)$ & $6.3(5.4)$ & $5.9(4.9)$ \\
\hline Range & $1-31$ & $1-37$ & $1-37$ \\
\hline \multicolumn{4}{|l|}{ Baseline EF domain score } \\
\hline Mean (SD) & $12.9(5.0)$ & $13.1(5.2)$ & $13.0(5.1)$ \\
\hline Range & 5-25 & $3-27$ & $3-27$ \\
\hline
\end{tabular}


rates were $78 \%$ with vardenafil $20 \mathrm{mg}$ and $29 \%$ with placebo $(p<0.001)$ (Fig. 3$)$.

Compared with placebo, patients treated with vardenafil had a statistically and clinically significant superiority in the IIEF-EF domain score at each visit $(p<0.001)$. The increase in IIEF-EF domain score in placebo-treated patients between baseline and week 12 was not clinically significant. A significantly larger proportion of patients with an IIEFEF domain score within the normal range $(\geq 26)$ was observed in the vardenafil group (61\%), compared with the placebo group (8\%), at each visit (ITT, last observation carried forward; $p<0.001$ ) (Fig. 4).

\section{Safety}

Vardenafil was well tolerated, with most AEs having mild-to-moderate intensity. Headache, flushing and nasal congestion, each reported by about $5 \%$ of vardenafil-treated patients, were the most frequently reported AEs. An additional 52 patients

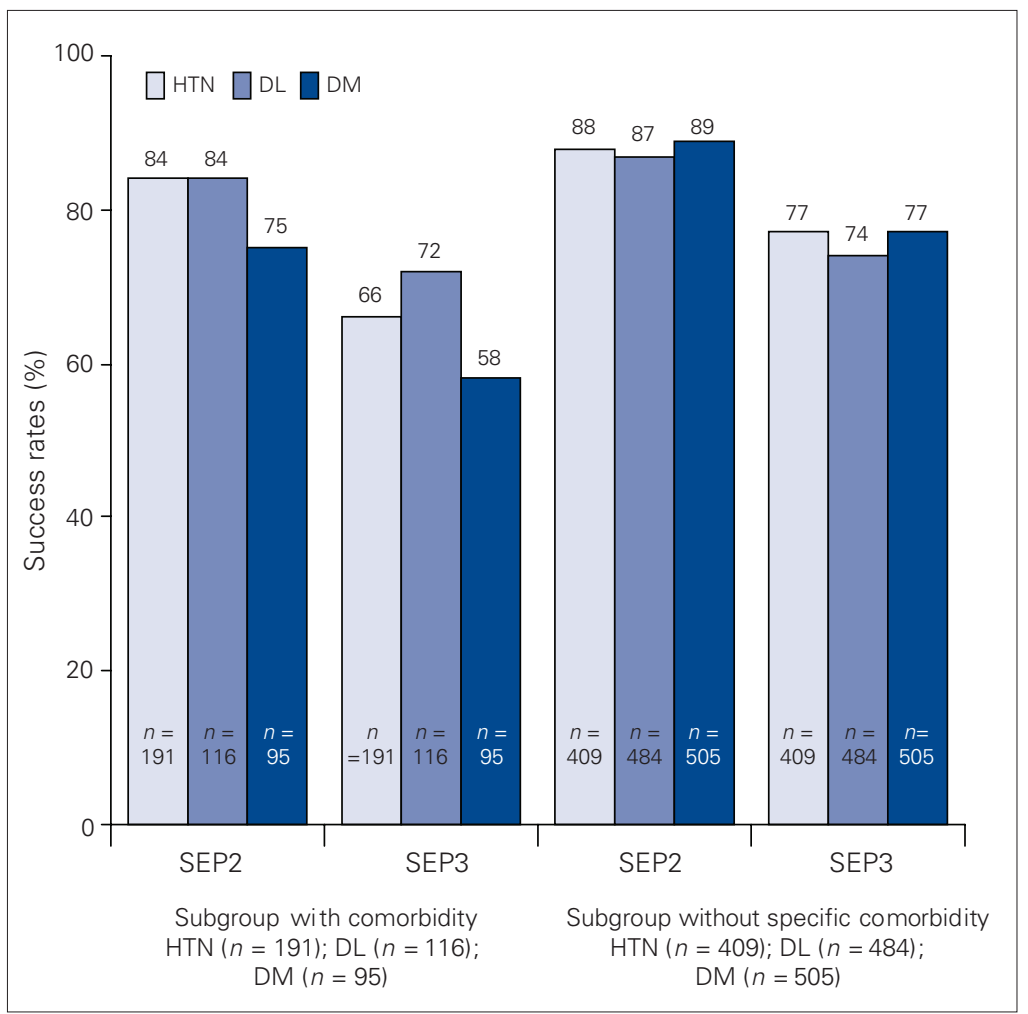

Fig. 2. First-dose SEP2 and SEP3 success rates in specific comorbidity subgroups during the open-label challenge phase. Presence or absence of a specific comorbidity did not preclude patients from having other associated comorbidities.

$\mathrm{DL}$ = dyslipidemia; $\mathrm{DM}$ = diabetes mellitus; HTN = hypertension; SEP2 = Sexual Encounter Profile, question 2; SEP3 = Sexual Encounter Profile, question 3.
(9.21\%) reported at least a single AE during the 1 -week challenge period. AEs occurring with an incidence $5 \%$ or higher in either treatment group are presented in Table 2. A total of 156 patients - $57(24.5 \%)$ in the placebo group and 99 $(43.0 \%)$ in the vardenafil group - reported at least 1 treatment-emergent $\mathrm{AE}$.

\section{Discussion}

The objective of this study was to evaluate the 12 -week reliability, efficacy and safety of vardenafil $20 \mathrm{mg}$ in men with ED who reported a first-dose success of vaginal penetration. This placebo-controlled trial was conducted after the similarly designed RELY-I study that evaluated vardenafil $10 \mathrm{mg}$ in patients with less severe ED and fewer associated comorbidities. Study limitations included the lack of investigator and patient blinding during the open-label challenge phase and the potential bias toward positive efficacy effects on patients in the placebo group at randomization. These are similar to the limitations found in the RELY-I study (owing to the shared study design) and should be considered when the results of this study are reviewed..$^{22}$ Results from our study demonstrated 12-week reliability with vardenafil $20 \mathrm{mg}$ and showed that this treatment regimen was highly successful, compared with placebo, as first-dose therapy for ED patients both with and without comorbidities. This also confirms earlier results reported by the RELY-I study. ${ }^{21,22}$ At the end of the RELY-I trial, the least squares mean reliability rate by dose in terms of SEP2 was $83.4 \%$ and in terms of SEP3, 76.5\%. ${ }^{21}$ Rates at the end of the RELY-II trial (SEP2, 85.0\%; SEP3, 78.5\%) were comparable and slightly higher than those in the RELY-I trial, despite the more severely ill patient population and corresponding lower baseline values. First-dose success rates were slightly lower overall in this study, compared with the RELY-I trial, which can be explained by the more severely ill patient population. However, considering the improved reliability rates discussed earlier, these lower first-dose success values with vardenafil $20 \mathrm{mg}$ have no impact on the reliability profile of this dose. It is important to remember when comparing data from clinical trials having the same or similar study designs that differences in baseline characteristics of patients enrolled in the trials may often produce clinical outcomes that are not 
expected or the same as those seen earlier. Therefore, evaluation of baseline patient characteristics is an essential facet and should be done while data from such studies are reviewed. Vardenafil $20 \mathrm{mg}$ was safe and well tolerated in patients with and without comorbidities. The AEs reported during the study were consistent with those seen in the RELY-I study. ${ }^{21,22}$

RELY-II IIEF-EF data further support the timeafter-time efficacy, that is, consistent and maintained improvement in erectile function parameters over time, reported in an earlier vardenafil trial that used IIEF questions 3 and 4 as the primary efficacy end points. ${ }^{23} \mathrm{~A}$ retrospective analysis of these results examined efficacy in terms of specific subgroup patient populations defined according to ED causes, ED severity and patient age. ${ }^{24}$ Similar future subgroup analyses from the RELY-I and RELY-II studies might shed more light on the reliability of vardenafil $10 \mathrm{mg}$ and $20 \mathrm{mg}$ in these and other subgroup patient populations.

Sustained efficacy and tolerability have been demonstrated with vardenafil $10 \mathrm{mg}$ and $20 \mathrm{mg}$ in men with ED over a longer period of 2 years. ${ }^{25}$ Long-term efficacy also has been demonstrated for sildenafil in a 1 - to 3 -year postobservational study. ${ }^{26}$ For tadalafil, there are no published data from studies with a similar long-term follow-up.

Interestingly, in the RELY-II study, $78 \%$ of patients had used sildenafil, and $9 \%$ tadalafil, before enrolment. A growing consensus in recent literature now suggests that ED patients whose PDE5-inhibitor treatment fails should be rechallenged with another agent. For instance, in this study, vardenafil significantly improved all efficacy parameters in patients who did not respond to sildenafil therapy. ${ }^{27}$

Vardenafil is the only PDE5 inhibitor for which first-dose success as assessed by key erectile function parameters has been studied exclusively in placebo-controlled trials rather than in retrospective analysis studies alone. ${ }^{20,21,28-30}$ Previously, firstdose success and/or reliability data for PDE5 inhibitors were available only from retrospective analysis of studies. ${ }^{28-30}$ In our study, with $34 \%$ of the men having severe $\mathrm{ED}, 41 \%$ having hypertension, $28 \%$ having dyslipidemia and $24 \%$ having diabetes, vardenafil $20 \mathrm{mg}$ demonstrated comparable if not superior reliability and first-time success in terms of SEP2 and SEP3 rates, compared with both sildenafil and tadalafil. ${ }^{28-30}$

\section{Conclusion}

Compared with placebo, vardenafil $20 \mathrm{mg}$ showed clinical and statistical superiority in continued successful penetration reliability over a 12-week study period. RELY-II results confirm and expand the retrospective analysis findings of Montorsi
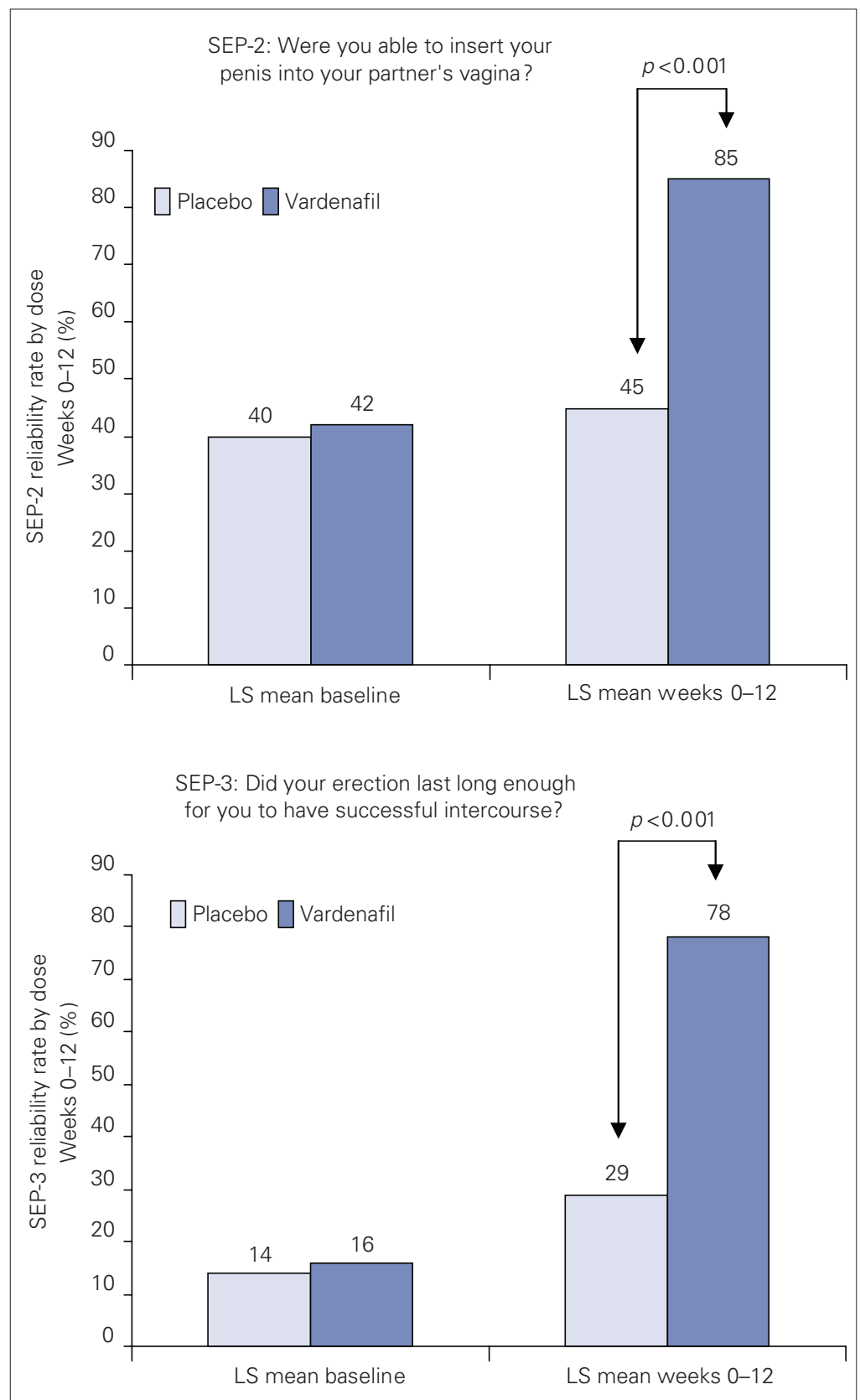

Fig. 3. Reliability of insertion (SEP2) and maintenance through intercourse (SEP3). LS = least squares; SEP2 = Sexual Encounter Profile, question 2; SEP3 = Sexual Encounter Profile, question 3. 


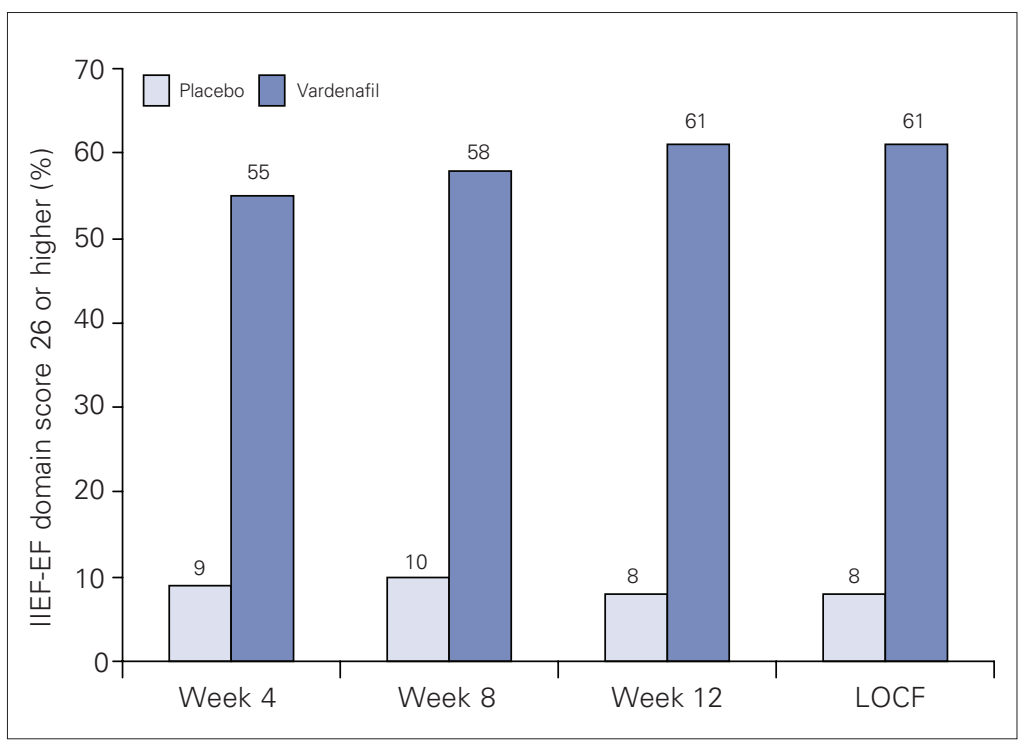

Fig. 4. Return to normal rates for IIEF-EF domain score, $p<0.001$ for all visits. IIEF-EF = International Index of Erectile Function-Erectile Function; LOCF = last observation carried forward.
This article has been peer reviewed.

Competing interests: Dr. Valiquette and Dr. Montorsi are investigators for, and are on the speaker's bureau of GlaxoSmithKline and Bayer. Dr. Auerbach has worked as a clinical investigator and consultant to GlaxoSmithKline.

\section{References}

1. McKinlay JB. The worldwide prevalence and epidemiology of erectile dysfunction. Int J Impot Res 2000;12(Suppl 4):S6-11.

2. NIH Consensus Conference. Impotence. NIH Consensus Development Panel on Impotence. JAMA 1993;270:83-90.

3. Fisher WA, Meryn S, Sand M, et al. Communication about erectile dysfunction among men with ED, partners of men with ED, and physicians: The Strike Up a Conversation Study (Part 1). J Men Health Gender 2005;2:64-78.

4. Simonsen U, Garcia-Sacristan A, Prieto D. Penile arteries and erection. J Vasc Res 2002;39:283-303

5. Nicolosi A, Moreira ED Jr, Villa M, et al. A population study of the association between sexual function, sexual satisfaction and depressive symptoms in men. J Affect Disord 2004:82:235-43.

6. Billups KL, Bank AJ, Padma-Nathan H, et al. Erectile dysfunction is a marker for cardiovascular disease: Results of the Minority Health Institute Expert Advisory Panel. J Sex Med 2005;2:40-50.

7. Lochmann A, Gallmetzer J. Erectile dysfunction of arterial origin as possible primary manifestation of atherosclerosis. Minerva Cardioangiol 1996;44:243-6.

8. Morley JE, Korenman SG, Kaiser FE, et al. Relationship of penile brachial pressure index to myocardial infarction and cerebrovascular accidents in older men. Am J Med 1988:84:445-8.

9. Seftel AD, Sun P, Swindle R. The prevalence of hypertension, hyperlipidemia, diabetes mellitus and depression in men with erectile dysfunction. J Urol 2004;171:2341-5.

10. Feldman HA, Goldstein I, Hatzichristou DG, et al. Impotence and its medical and psychosocial correlates: results of the Massachusetts Male Aging Study. J Urol 1994; 151: 54-61.

11. Doumas M, Tsakiris A, Douma S, et al. Factors affecting the increased prevalence of erectile dysfunction in Greek hypertensive compared to normotensive subjects. J Androl 2006:27:469-77.

12. Thompson IM, Tangen $C M$, Goodman PJ, et al. Erectile dysfunction and subsequent cardiovascular disease. JAMA 2005;294:2996-3002.

and colleagues, ${ }^{28}$ as well as the reliability findings of the RELY-I study. ${ }^{21,22}$ Despite a high proportion of patients with severe ED and with concomitant comorbidities, the RELY-II study demonstrated that most patients who respond initially to vardenafil $20 \mathrm{mg}$ are likely to experience successful intercourse (penetration and maintenance of erection to completion) on their subsequent attempts at a probability similar to their first-dose success.

From *Hôpital St-Luc du CHUM, Montréal, Que., †Universita Vita Salute San Raffaele, Milan, Italy, and ¥California Professional Research, Newport Beach, Calif.

Acknowledgements: The authors thank Jose Iglesia, MD, and Shabber Abbas, BSc, for their editorial assistance with this manuscript. This study was supported by GlaxoSmithKline, King of Prussia, PA, and Bayer Healthcare, Pharmaceutical Division, West Haven, CT.
13. Greenstein A, Chen J, Miller H, et al. Does severity of ischemic coronary disease correlate with erectile function? Int J Impot Res 1997:9:123-6.

14. O'Leary MP, Fowler FJ, Lenderking WR, et al. A brief male sexual function inventory for urology. Urology 1995;46:697-706.

15. Goldman L, Hashimoto B, Cook E, et al. Comparative reproducibility and validity of systems for assessing cardiovascular functional class: advantages of a new specific activity scale. Circulation 1981;64:1227-34.

16. Eardley I, Rosen R, Fisher WA, et al. What men want: desired attributes of ED therapy among men with ED in the MALES 2004 study. J Sex Med 2004;42(Suppl 1):Abstract 044.

17. Kwok YS, Kim C. Valuing Viagra: what is restoring potency worth? Eff Clin Pract 1999;2:171-5.

18. American Urological Association. Management of Erectile Dysfunction ('05/Updated '06). Available: www.auanet.org/guidelines/edmgmt. ffm (accessed 2007 Jan 17).

19. Meuleman EJ, Eardley I, Rosen R, et al. Attitudes toward treatment of erectile dysfunction: results from the MALES (Men's Attitudes toward Life Events and Sexuality) study. Presented at the Annual Meeting of the Asian Pacific Society of Sexual and Impotence Research, Cebu, Philippines, 2003 Oct.l-4.

20. Eardley I, Rosen R, Fisher WA, et al. Attitudes toward treatment of erectile dysfunction: results from the MALES study [Abstract 377]. Eur Urol Suppl 2003;2:97.

21. Valiquette L, Young JM, Moncada I, et al.; Vardenafil Study Group. Sustained efficacy 
and safety of vardenafil for treatment of erectile dysfunction: a randomized, doubleblind, placebo-controlled study. Mayo Clin Proc 2005;80:1291-7.

22. Valiquette L, Montorsi F, Auerbach S; Vardenafil Study Group. First-dose success with vardenafil in men with erectile dysfunction and associated comorbidities: RELYII. Int J Clin Pract 2006;60:1378-85.

23. Porst $H$, Rosen R, Padma-Nathan $H$, et al. The efficacy and tolerability of vardenafil, a new, oral, selective phosphodiesterase type 5 inhibitor, in patients with erectile dysfunction: the first at-home clinical trial. Int I Impot Res 2001;13:192-9.

24. Porst H, Young JM, Schmidt AC, et al.; International Vardenafil Study Group. Efficacy and tolerability of vardenafil for treatment of erectile dysfunction in patient subgroups. Urology 2003;62:519-23; discussion 523-524.

25. Stief C, Porst H, Saenz De Tejada I, et al.; Vardenafil Study Group. Sustained efficacy and tolerability with vardenafil over 2 years of treatment in men with erectile dysfunction. Int I Clin Pract 2004;58:230-9.

26. Sheu JY, Chen KK, Lin AT, et al. Long-term efficacy and safety of sildenafil for patients with erectile dysfunction. J Chin Med Assoc 2003;66:480-6.

27. Carson $\mathrm{CC}$, Hatzichristou D, Carrier $\mathrm{S}$, et al. Vardenafil exhibits efficacy in men with erectile dysfunction unresponsive to prior sildenafil therapy: results of a phase-III clinical trial - patient response with vardenafil in sildenafil nonresponders (PROVEN). Int J Impot Res 2003;15(Suppl 5):S175.

28. Montorsi F, Hellstrom WJ, Valiquette L, et al. North American and European Vardenafil Groups. Vardenafil provides reliable efficacy over time in men with erectile dysfunction. Urology 2004;64:1187-95.

29. McCullough AR, Barada JH, Fawzy A, et al. Achieving treatment optimization with sildenafil citrate (Viagra) in patients with erectile dysfunction. Urology 2002;60(Suppl 2):28-38.

30. Schulman CC, Shen W, Stothard DR, et al. Integrated analysis examining first-dose success, success by dose, and maintenance of success among men taking tadalafil for erectile dysfunction. Urology 2004;64:783-8.

Correspondence: Dr. Luc Valiquette, Hôpital St-Luc du CHUM, 1058 rue St Denis, Montréal QC H2X 3J4; lucval@videotron.ca

\section{CUA PATIENT INFORMATION BROCHURES}

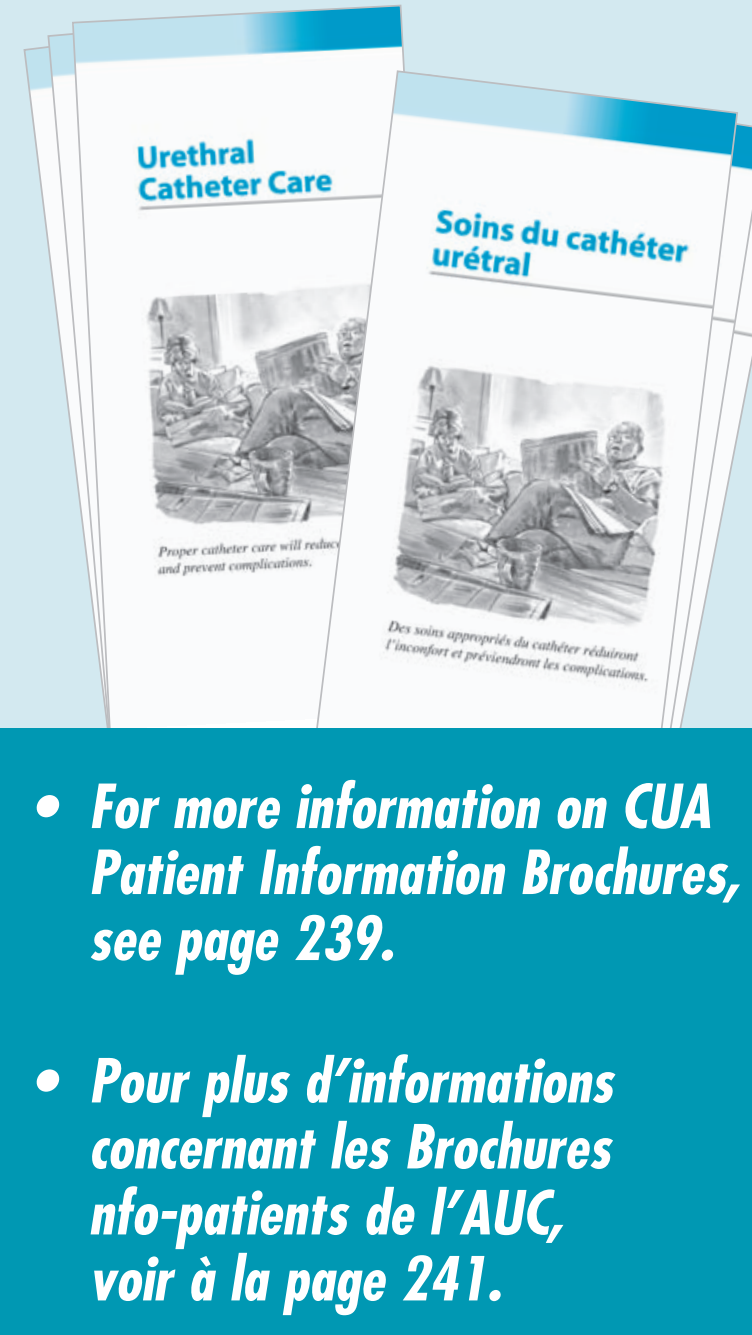

